\title{
Fatores determinantes em processos de transferência de conhecimentos: um estudo de caso na Embrapa Milho e Sorgo e firmas licenciadas'
}

\author{
José Márcio de Castro \\ Pontifícia Universidade Católica de Minas Gerais \\ Daniela Martins Diniz \\ Pontifícia Universidade Católica de Minas Gerais \\ Roberto Gonzalez Duarte \\ Universidade Federal de Minas Gerais \\ Marcelo Dressler \\ Embrapa Milho e Sorgo \\ Rodrigo Baroni de Carvalho \\ Pontifícia Universidade Católica de Minas Gerais
}

\begin{abstract}
A literatura sobre transferência de conhecimento tem privilegiado uma perspectiva unidimensional na análise de fatores que influenciam esse processo. Argumenta-se, neste artigo, que diferentes fatores relativos tanto ao contexto relacional quanto ao contexto organizacional influenciam o processo de transferência de conhecimento entre organizações. A fim de analisar a influência desses fatores no processo de transferência de conhecimento, realizou-se um estudo de caso qualitativo na Embrapa Milho e Sorgo. Os resultados mostram que fatores do contexto relacional, tal como a baixa conexão e integração entre as organizações (fonte e receptora), e fatores do contexto organizacional, tais como a baixa capacidade absortiva da receptora e a baixa motivação (aprender e ensinar) das duas partes (fonte e receptora), afetam negativamente o processo de transferência de conhecimento.
\end{abstract}

PalaVRas-chave: transferência de conhecimento; fatores críticos; agronegócio.

Artigo recebido em 20 set. 2012 e aceito em 17 jul. 2013.

${ }^{1}$ Agradecemos à Embrapa Milho e Sorgo (Empresa Brasileira de Pesquisa Agropecuária) o apoio e o amplo acesso aos dados e à Fundação de Amparo à Pesquisa do Estado de Minas Gerais (Fapemig) o suporte financeiro para a realização da pesquisa. 
Factores determinantes en el proceso de transferencia del conocimiento: un estudio de caso en Embrapa Milho y Sorgo y firmas licenciadas

La literatura sobre transferencia de conocimiento aún contempla una perspectiva unidimensional en el análisis de los factores que influyen en dicho processo. Argumenta-se, en este artículo, que diferentes factores relacionados con el contexto relacional y con el contexto organizacional afectan el proceso de transferencia de conocimiento entre las organizaciones. Con el fin de analizar la influencia de esos factores en el proceso de transferencia de conocimiento, ha sido realizado un estudio de caso cualitativo en la Embrapa Milho e Sorgo. Los resultados ponen de manifiesto que la baja conexión e integración entre las partes (factores del contexto relacional) e la baja capacidad de absorción de las receptoras y baja motivación (enseñar y aprender) de las partes (factores del contexto organizacional) tienen influencias significativas sobre el éxito de la transferencia de conocimiento.

Palabras clave: transferencia de conocimiento; fatores críticos; agronegócio.

Critical determinants within knowledge transfer processes: a case study at Embrapa

The literature on knowledge transfer has favored a one dimensional approach of factors influencing this process. We argue, in this article, that different factors from both the relational context as well as from the organizational context may affect the process of knowledge transfer among organizations. In order to analyze the influence of these factors on the knowledge transfer process, a qualitative case study was carried out at Embrapa. Results have demonstrated low social connection and integration between the parts (relational context factor) and low absorptive capacity of recipient organizations and low motivation of parts (organizational context factors) affect negatively the process of knowledge transfer between organizations.

KeYwoRDs: knowledge transfer; critical factors; agribusiness.

\section{Introdução}

A transferência de conhecimento interorganizações tem sido objeto de inúmeros estudos e pesquisas, notadamente a partir da década de 1990, quando se tornou evidente que a aquisição de conhecimentos externos poderia contribuir para a inovação e a competitividade das organizações (Easterby-Smith, Lyles e Tsang, 2008; Pérez-Nordtvedt et al., 2008). A partir daí, vários estudiosos se dedicaram a investigar os fatores antecedentes que poderiam induzir ou inibir o fluxo de conhecimento entre as organizações (Van Wijk, Jansen e Lyles, 2008).

Todavia, essa literatura tem, por um lado, adotado uma perspectiva unidimensional na análise do fenômeno explicando a influência de fatores únicos na transferência de conhecimento (a esse respeito, veja, por exemplo, Pérez-Nordtvedt et al., 2008). Apenas mais recentemente privilegiou-se uma perspectiva multidimensional (veja, por exemplo, EasterbySmith, Lyles e Tsang, 2008; Pérez-Nordtvedt et al., 2008), na qual vários fatores concorrem para explicar tal processo. Por outro, a literatura tem tratado o fenômeno como um ato único e instantâneo, mas, na realidade, a transferência é mais do que um simples ato de transmissão e recepção. Trata-se de um processo de reconstrução do conhecimento na firma receptora (Szulanski, 2000) que envolve diferentes etapas - aquisição, assimilação, transformação e 
exploração do conhecimento — , constituindo-se, assim, em uma atividade complexa, interativa e dinâmica (Bresman, Birkinshaw e Nobel, 1999; Pérez-Nordtvedt et al., 2008). Por fim, a transferência de conhecimento abarca diferentes contextos (organizacional e relacional), os quais incluem diversos fatores que afetam esse processo. Contudo, o papel desses fatores não foi, ainda, adequadamente compreendido (Szulanski, 1996, 2000).

Assim, o objetivo deste artigo é identificar e analisar o papel dos fatores antecedentes no processo de transferência de conhecimento interorganizações. Do ponto de vista do contexto relacional, examinam-se os fatores que permeiam a dinâmica das relações entre a fonte e a receptora (confiança, intensidade de vínculos e proximidade cultural entre as partes). Do ponto de vista do contexto organizacional, analisam-se os fatores relacionados ao contexto da fonte (motivação para ensinar, domínio de conhecimentos valiosos e capacidade para transferir) e ao contexto da receptora (motivação para aprender e capacidade absortiva).

Com a finalidade de discutir o papel desses fatores antecedentes, analisou-se o caso da transferência de conhecimentos entre a Embrapa Milho e Sorgo - que desenvolve pesquisas e tecnologias de milho e sorgo - e as empresas licenciadas, que fazem parte da cadeia produtiva e são selecionadas, atualmente, por meio de um processo público de licenciamento (Dressler, 2009).

Os resultados sugerem que, no processo de transferência de conhecimento entre a instituição de pesquisa e as empresas licenciadas, a conexão social e a integração entre as partes têm influências significativas para o resultado desse processo. Especificamente, a baixa intensidade de vínculos e a divergência de valores e crenças podem dificultar a transferência mais efetiva de conhecimento. Os resultados apontam ainda que a capacidade absortiva das receptoras e a motivação das partes (para aprender e ensinar) têm particular importância para os resultados do processo de transferência. A principal contribuição deste artigo para a literatura é a análise do processo de transferência a partir de uma perspectiva multidimensional, ou seja, compreender como o processo de transferência de conhecimento e o resultado desse processo são afetados pelos diversos fatores e, ainda, como esses fatores se inter-relacionam.

Para além dessa introdução, o artigo está estruturado em quatro seções. Na primeira, apresenta-se uma revisão crítica da literatura, com os avanços na compreensão dos fatores antecedentes para a transferência de conhecimento interorganizacional. Em seguida, descrevem-se os procedimentos metodológicos. Na terceira parte, são apresentadas e discutidas as evidências do caso analisado. Por fim, são apresentadas as principais conclusões, as implicações para as organizações, as contribuições teóricas e as limitações da pesquisa.

\section{Revisão da literatura}

Nesta seção, faz-se uma revisão da literatura sobre transferência de conhecimento. Discutemse, especificamente, como os fatores do contexto relacional e do contexto organizacional da fonte e da receptora podem afetar o processo de transferência do conhecimento. 


\subsection{Fatores do contexto relacional determinantes para a transferência de conhecimentos}

A transferência de conhecimento é, por diversas razões, fonte importante de competitividade e inovação das firmas (Love e Roper, 1999; Argote e Ingram, 2000; Van Wijk, Jansen e Lyles, 2008). Em primeiro, a transferência de conhecimento permite a qualquer organização, ao menos potencialmente, adquirir, transformar e utilizar um conhecimento externo, o que pode resultar em inovação - de produtos, processos e serviços - e desempenho superior (Argote e Ingram, 2000; Lin, 2003; Child et al., 2012; Van Wijk, Jansen e Lyles, 2008). A transferência permite, também, que mesmo organizações com recursos limitados para o desenvolvimento interno de atividades de P\&D (Pesquisa e Desenvolvimento) poderiam inovar, mediante a aquisição de conhecimentos externos (Cohen e Levinthal, 1990).

A transferência de conhecimento entre organizações é um processo por meio do qual os atores organizacionais - equipe, unidade ou firma - trocam conhecimentos e são mutuamente influenciados por essa experiência (Argote e Ingram, 2000; Easterby-Smith, Lyles e Tsang, 2008; Van Wijk, Jansen e Lyles, 2008). Entretanto, o processo de transferência requer, além da aquisição do conhecimento externo, sua transformação e aplicação pela unidade receptora (Cummings e Teng, 2003). Como essa transferência pressupõe conexão entre as partes, barreiras de relacionamento, por exemplo, podem dificultar o processo (Szulanski, 1996; Easterby-Smith, Lyles e Tsang, 2008).

O contexto relacional se refere ao relacionamento entre a firma doadora e a receptora (Argote, McEvily e Reagans, 2003; Easterby-Smith, Lyles e Tsang, 2008). Tendo em vista a relevância do relacionamento para a transferência de conhecimento (Easterby-Smith, Lyles e Tsang, 2008), um fator crítico é a conexão e a integração entre as partes, a qual inclui atributos, tais como (i) intensidade de vínculos; (ii) confiança entre as partes; e (iii) proximidade cultural.

Esses atributos afetam a transferência, uma vez que interações mais próximas e frequentes tendem a favorecer a troca de experiências (Van Wijk, Jansen e Lyles, 2008), facilitando, consequentemente, a absorção do conhecimento transferido (Pérez-Nordtvedt et al., 2008). A confiança, por sua vez, facilita a transferência ao criar uma sensação de segurança de que o conhecimento transferido não será explorado para além do que foi acordado (Easterby-Smith, Lyles e Tsang, 2008). Quando as organizações desenvolvem vínculos mais estreitos e há confiança entre as partes, elas, geralmente, estão mais dispostas a compartilhar conhecimentos e, assim, a transferência tende a ocorrer de forma mais rápida. Em suma, relacionamentos de qualidade influenciam na velocidade e na economia da transferência, que são medidas de eficiência do processo (Pérez-Nordtvedt et al., 2008). O terceiro atributo relacionado à conexão e à integração entre as partes é proximidade cultural, que pressupõe a existência de significados comuns e de sistemas de valores similares entre as partes (Cummings e Teng, 2003; Van Wijk, Jansen e Lyles, 2008). Essa proximidade é relevante, pois pode ampliar a integração social, concorrendo para reforçar a confiança e a intensidade de vínculos entre as organizações

(DeTienne et al., 2004). Entretanto, diferenças de valores, de práticas e de objetivos entre 
as organizações contribuem para relacionamentos mais conflituosos, dificultam a comunicação e podem distorcer o significado do conhecimento (Easterby-Smith, Lyles e Tsang, 2008), afetando o processo de transferência de conhecimento (Cummings e Teng, 2003; Van Wijk, Jansen e Lyles, 2008).

Individual ou conjuntamente, esses atributos — intensidade do vínculo, confiança e proximidade cultural — podem indicar uma maior ou menor conexão e integração entre as partes (quadro 1) e podem influenciar os resultados da transferência de conhecimento (Vinding, 2004).

Quadro 1

Síntese teórica dos fatores do contexto relacional

\begin{tabular}{|c|c|c|c|}
\hline Categoria & Atributos & Operacionalização & Autores \\
\hline \multirow{3}{*}{$\begin{array}{l}\text { Conexão e integração } \\
\text { entre as partes }\end{array}$} & $\begin{array}{l}\text { Intensidade de } \\
\text { Vínculos }\end{array}$ & $\begin{array}{l}\text { Interações mais próximas e frequentes; } \\
\text { vínculos estreitos. }\end{array}$ & $\begin{array}{l}\text { Van Wijk, Jansen e Lyles (2008); Pérez- } \\
\text { Nordtvedt e colaboradores (2008); } \\
\text { DeTienne e colaboradores (2004); } \\
\text { Vinding (2004) }\end{array}$ \\
\hline & Confiança & $\begin{array}{l}\text { Sensação de segurança entre as } \\
\text { partes. }\end{array}$ & Easterby-Smith, Lyles e Tsang (2008) \\
\hline & $\begin{array}{l}\text { Proximidade } \\
\text { Cultural }\end{array}$ & $\begin{array}{l}\text { Existência de significados comuns; } \\
\text { sistemas de valores similares entre as } \\
\text { partes. }\end{array}$ & $\begin{array}{l}\text { Cummings e Teng (2003); Van Wijk, } \\
\text { Jansen e Lyles (2008); Easterby-Smith, } \\
\text { Lyles e Tsang (2008) }\end{array}$ \\
\hline
\end{tabular}

Fonte: Elaborado pelos autores.

\subsection{Fatores do contexto organizacional determinantes para a transferência de conhecimento}

Em relação aos fatores do contexto organizacional que influenciam o processo de transferência de conhecimento, a literatura aponta, do lado da receptora: (i) a capacidade absortiva (Cohen e Levinthal, 1990; Zahra e George, 2002); e (ii) a motivação para aprender (Szulanski, 1996, 2000; Pérez-Nordtvedt et al., 2008; Easterby-Smith, Lyles e Tsang, 2008). Do lado da fonte, os fatores mais relevantes são: (i) a motivação para ensinar (Szulanski, 1996, 2000; Easterby-Smith, Lyles e Tsang, 2008); (ii) a capacidade para transferir conhecimento (Hansen, Nohria e Tierney, 1999; Sun e Scott, 2005); e (iii) a posse de conhecimentos valiosos (Pérez-Nordtvedt et al., 2008).

\subsubsection{Contexto organizacional da receptora}

A capacidade absortiva (CA) pode ser entendida como a capacidade da organização em identificar, assimilar, explorar e utilizar o conhecimento externo (Cohen e Levinthal, 1990; 
Zahra e George, 2002). Para a receptora, a CA é crítica, pois a simples aquisição do conhecimento externo não assegura sua utilização de maneira eficaz, podendo tal conhecimento ser utilizado indevidamente ou, simplesmente, não ser utilizado. A firma receptora deve, em particular, ter competência organizacional para assimilar, transformar e utilizar o conhecimento externo, incorporando-o em suas rotinas e aplicando-o na melhoria de produtos e processos (Cohen e Levinthal, 1990; Zahra e George, 2002). Diversos atributos podem indicar o nível de CA de uma firma.

Um desses atributos é o nível de qualificação dos empregados, uma vez que a CA das organizações depende, em última instância, da CA dos indivíduos (Cohen e Levinthal, 1990). Vinding (2004), investigando a interação entre firmas industriais e instituições do conhecimento (universidades, centros de educação tecnológica, institutos de pesquisa), constatou que tal interação aumenta o potencial das primeiras em explorar o conhecimento e promover inovações em produtos, especialmente quando contam com empregados altamente qualificados. Outro atributo está relacionado ao nível de investimento em P\&D na organização, pois tais atividades contribuem para estimular a aprendizagem (Cohen e Levinthal, 1990). Um terceiro é a compatibilidade entre o conhecimento externo e o conhecimento prévio da receptora, posto que os indivíduos assimilam melhor conceitos dentro dos domínios de sua área imediata de conhecimento (Cohen e Levinthal, 1990). Assim, o conjunto de conhecimentos e competências de uma organização resultante de suas experiências pode contribuir para aumentar sua CA e, em consequência, sua expertise no acúmulo de novas capacidades em um período subsequente (path dependence) (Cohen e Levinthal, 1990). Por fim, um quarto atributo, a presença de uma cultura orientada para a inovação, pode favorecer o desenvolvimento da CA da firma, pois cria condições favoráveis à interação, à comunicação e à aprendizagem, facilitando, assim, a exploração dos conhecimentos externos (Cohen e Levinthal, 1990; Cummings e Teng, 2003).

Portanto, elevados níveis de CA facilitam a aquisição, assimilação e utilização do conhecimento externo, o que sugere uma relação direta e positiva entre a CA e o desempenho na transferência de conhecimento. Portanto, quanto maior a CA, mais fácil será o intercâmbio entre a receptora e a fonte do conhecimento externo (Van Wijk, Jansen e Lyles, 2008). Entretanto, Cribb, Maia e Cribb (2006), analisando a transferência de conhecimento de instituições de pesquisa para empresas comerciais, argumentam que barreiras à transferência decorrem tanto da natureza da tecnologia quanto dos comportamentos dos atores.

Nesses termos, outro fator do lado da receptora é a motivação para aprender. A percepção, por parte da receptora, de que a fonte detém um conhecimento valioso aumenta a motivação para absorver esse conhecimento e para superar potenciais dificuldades inerentes à transferência (Pérez-Nordtvedt et al., 2008). Desse modo, a motivação da receptora está relacionada à atratividade da fonte (Gupta e Govindarajan, 2000; Pérez-Nordtvedt et al., 2008; Becerra, Lunnan e Huemer, 2008). Ou seja, se o conhecimento é entendido como valioso e se a fonte é percebida como detentora de experiência e reputação na criação e na transferência de conhecimentos, a receptora tende a estar mais motivada em absorver o conhecimento 
externo, o que favorece o processo de transferência (Pérez-Nordtvedt et al., 2008; Albino, Garavelli e Schiuma, 1999; Argote, McEvily e Reagans, 2003).

Por outro lado, a ausência de motivação da receptora em relação à transferência de conhecimento pode ser resultante de algumas causas. Primeiro, a fonte pode não ser percebida como atrativa e/ou seu conhecimento não ser relevante para a receptora (Easterby-Smith, Lyles e Tsang, 2008). Em segundo, o desinteresse da receptora no conhecimento externo pode sinalizar para uma baixa capacidade de absorção e retenção (Szulanski, 1996, 2000). E, por fim, a motivação da receptora pode ser afetada caso perceba que o conhecimento externo é complexo e/ou ambíguo (Argote, McEvily e Reagans, 2003; Simonin, 1999).

\subsubsection{Contexto organizacional da fonte}

Do lado da fonte, a motivação diz respeito ao interesse ou à disposição em ensinar e transferir o conhecimento para outras organizações (Lin, 2003; Easterby-Smith, Lyles e Tsang, 2008). Um atributo determinante dessa motivação é se a criação e a transferência de conhecimentos fazem parte da estratégia da organização (Smilor e Gibson, 1991). De outra maneira, a motivação da fonte pode, também, ser influenciada negativamente pela percepção de que o repasse de um conhecimento, base de sua competitividade, é arriscado e, assim, ela estaria menos disposta a transferir seu conhecimento (Sun e Scott, 2005; Easterby-Smith, Lyles e Tsang, 2008). Uma percepção de baixa CA da receptora pode, também, afetar negativamente a motivação da fonte para a transferência (Szulanski, 2000). Entretanto, alguns fatores podem moderar essa motivação. Por exemplo, uma relação mais próxima e de confiança com a receptora pode minimizar o receio da fonte em compartilhar o seu conhecimento (Becerra, Lunnan e Huemer, 2008).

Outro fator relacionado à fonte é sua capacidade de transferência de conhecimento, pois, como observam Hansen, Nohria e Tierney (1999), embora as partes possam estar motivadas, a fonte pode ser incapaz de transferi-lo. Essa incapacidade (Sun e Scott, 2005) pode inibir o processo de compartilhamento de conhecimento. A capacidade de transferir conhecimento depende, entre outras coisas, da presença de recursos humanos qualificados, de recursos tecnológicos e, também, da escolha adequada de mecanismos para realizar a transferência. Tais mecanismos incluem: (i) treinamentos dos membros da firma receptora; (ii) atividades de socialização (visitas, encontros e reuniões); (iii) intercâmbio de indivíduos experientes para difundir o conhecimento; e (iv) elaboração de manuais, modelos e uso de sistemas de informação (Easterby-Smith, Lyles e Tsang, 2008). A escolha de mecanismos adequados para a transferência de conhecimento depende da natureza do conhecimento. Se o conhecimento é tácito, as atividades de socialização podem ser mais efetivas (Cummings e Teng, 2003; Bresman, Birkinshaw e Nobel, 1999).

Os fatores relacionados com o contexto organizacional da fonte e da receptora de conhecimento estão sintetizados no quadro 2. 
Quadro 2

Síntese teórica dos fatores do contexto organizacional da fonte e da receptora

\begin{tabular}{|c|c|c|c|}
\hline Categoria & Atributos & Operacionalização & Autores \\
\hline \multirow{4}{*}{$\begin{array}{l}\text { Capacidade } \\
\text { absortiva da } \\
\text { receptora }\end{array}$} & $\begin{array}{l}\text { Nível de qualificação dos } \\
\text { empregados }\end{array}$ & $\begin{array}{l}\text { Elevados níveis de qualificação } \\
\text { dos empregados potencializam a } \\
\text { capacidade absortiva. }\end{array}$ & $\begin{array}{l}\text { Cohen e Levinthal (1990); } \\
\text { Zahra e George (2002); } \\
\text { Vinding (2004) }\end{array}$ \\
\hline & $\begin{array}{l}\text { Nível de investimento em } \\
\text { atividades internas de P\&D }\end{array}$ & $\begin{array}{l}\text { Atividades de P\&D contribuem } \\
\text { para estimular a aprendizagem dos } \\
\text { indivíduos. }\end{array}$ & $\begin{array}{l}\text { Cohen e Levinthal (1990); } \\
\text { Zahra e George (2002) }\end{array}$ \\
\hline & $\begin{array}{l}\text { Compatibilidade entre o } \\
\text { conhecimento externo e } \\
\text { o conhecimento prévio da } \\
\text { receptora }\end{array}$ & $\begin{array}{l}\text { Os indivíduos assimilam mais } \\
\text { facilmente conceitos dentro dos } \\
\text { limites de sua área imediata de } \\
\text { conhecimento. }\end{array}$ & Cohen e Levinthal (1990) \\
\hline & $\begin{array}{l}\text { Cultura orientada para a } \\
\text { inovação }\end{array}$ & $\begin{array}{l}\text { Condições que favorecem a } \\
\text { interação, a comunicação e } \\
\text { aprendizagem dos indivíduos. }\end{array}$ & Cohen e Levinthal (1990) \\
\hline $\begin{array}{l}\text { Domínio de } \\
\text { conhecimentos } \\
\text { valiosos por parte } \\
\text { da fonte }\end{array}$ & $\begin{array}{l}\text { Reputação na criação } \\
\text { e transferência de } \\
\text { conhecimentos valiosos }\end{array}$ & $\begin{array}{l}\text { O conhecimento da fonte é } \\
\text { percebido como valioso. }\end{array}$ & $\begin{array}{l}\text { Pérez-Nordtvedt et e } \\
\text { colaboradores (2008) }\end{array}$ \\
\hline $\begin{array}{l}\text { Motivação da } \\
\text { receptora }\end{array}$ & Interesse em aprender & $\begin{array}{l}\text { Relacionado ao valor do } \\
\text { conhecimento da fonte e sua } \\
\text { reputação em criar e transferir } \\
\text { conhecimentos. }\end{array}$ & $\begin{array}{l}\text { Gupta e Govindarajan } \\
\text { (2000); Pérez-Nordtvedt e } \\
\text { colaboradores (2008); } \\
\text { Becerra, Lunnan e Huemer } \\
\text { (2008); Argote, McEvily e } \\
\text { Reagans (2003) }\end{array}$ \\
\hline Motivação da fonte & $\begin{array}{l}\text { Interesse em ensinar e } \\
\text { transferir o conhecimento }\end{array}$ & $\begin{array}{l}\text { Relacionada com a confiança, } \\
\text { a capacidade da receptora em } \\
\text { absorver conhecimentos. }\end{array}$ & $\begin{array}{l}\text { Lin (2003); Easterby-Smith, } \\
\text { Lyles e Tsang (2008) }\end{array}$ \\
\hline $\begin{array}{l}\text { Capacidade } \\
\text { de transferir } \\
\text { conhecimentos }\end{array}$ & $\begin{array}{l}\text { Recursos adequados } \\
\text { para a transferência de } \\
\text { conhecimento }\end{array}$ & $\begin{array}{l}\text { Relacionada com a presença de } \\
\text { recursos humanos qualificados, } \\
\text { recursos tecnológicos e } \\
\text { mecanismos adequados. }\end{array}$ & $\begin{array}{l}\text { Hansen, Nohria e Tierney } \\
\text { (1999); } \\
\text { Sun e Scott (2005) }\end{array}$ \\
\hline
\end{tabular}

Fonte: Elaborado pelos autores.

\section{Metodologia da pesquisa}

Com o objetivo de compreender o papel dos fatores antecedentes para a transferência de conhecimento entre organizações, optou-se por uma pesquisa de natureza qualitativa com o uso do método de estudo de caso (Greenwood, 1973; Bonoma, 1985; Yin, 2005). A estratégia do estudo de caso é mais relevante quando o tema é recente e ainda não há um consenso na teoria (Yin, 1981; Bonoma, 1985) ou, ainda, quando as variáveis estão inter-relacionadas (Yin, 2005), como é o caso na transferência de conhecimento. 
Escolhida a estratégia de pesquisa, a seleção de casos é uma decisão crucial, pois pode influenciar na relevância dos resultados do estudo (Eisenhardt, 1989). O objetivo da seleção é escolher casos que possam replicar ou estender uma teoria emergente (Eisenhardt, 1989). Nestes termos, selecionou-se para o estudo a Empresa Brasileira de Pesquisa Agropecuária (Embrapa) ou, mais precisamente, a Embrapa Milho e Sorgo, um dos centros de pesquisa da Embrapa (documento 4).

A seleção desse centro de pesquisa da Embrapa foi feita com base nos seguintes critérios: (i) a Embrapa é a maior empresa pública de pesquisa agropecuária brasileira; (ii) tem ampla experiência em processos de transferência de conhecimento; (iii) já utilizou diversas estratégias de transferência de suas tecnologias para o setor produtivo; e, por fim, (iv) o acesso amplo aos dados possibilitou a coleta de um volume considerável de dados, contribuindo, assim, para a riqueza dos resultados do estudo.

Esta pesquisa utilizou-se, preferencialmente, de entrevistas em profundidade, documentos e arquivos como fontes de evidências. Com base na literatura, dois tipos de roteiros de entrevistas foram elaborados: um para os colaboradores da Embrapa Milho e Sorgo (MG) e outro para os gestores das empresas licenciadas. Entre os principais tópicos abordados nos roteiros de entrevistas podem-se destacar: (i) processo de transferência; (ii) relacionamento entre a instituição de pesquisa e as empresas licenciadas; (iii) atratividade em relação às tecnologias da instituição; (iv) qualificação dos empregados das empresas licenciadas; (v) capacidade tecnológica das empresas licenciadas; (vi) mecanismos de transferência; e (vii) resultados do processo de transferência.

Realizaram-se 12 entrevistas em profundidade. Todos os respondentes estavam envolvidos em atividades de P\&D, planejamento e gestão, comunicação e tecnologia e detinham, então, informações cruciais sobre o processo de transferência de conhecimento, conforme quadro 3.

$$
\text { Quadro } 3
$$

\section{Relação das entrevistas conduzidas na pesquisa}

\begin{tabular}{|cc|}
\hline Ordem & Setor de trabalho do respondente \\
\hline 1 & Área de Negócio Tecnológico \\
2 & Área de Negócio Tecnológico \\
3 & Escritório de Transferência de Tecnologia de Sete Lagoas \\
4 & Área de Negócio Tecnológico \\
5 & Escritório de Transferência de Tecnologia de Sete Lagoas \\
6 & Área de Negócio Tecnológico \\
7 & Escritório de Transferência de Tecnologia do Triângulo Mineiro \\
8 & Área de Comunicação e Negócio Tecnológico \\
9 & Área de Comunicação Empresarial \\
10 & Área de Pesquisa e Desenvolvimento \\
11 & Consultor de uma empresa licenciada \\
12 & Diretor de uma empresa licenciada \\
\hline
\end{tabular}

Fonte: Elaborado pelos autores. 
Além das entrevistas em profundidade, utilizaram-se fontes secundárias, isto é, documentos da Embrapa Nacional e Embrapa Milho e Sorgo, tais como planos e relatórios gerenciais, material de divulgação, relatórios de pesquisa, notícias e os portais da instituição e de suas unidades, que são ricos em informações. O quadro 4 relaciona o conjunto de documentos utilizados como fonte da pesquisa.

$$
\text { Quadro } 4
$$

\section{Relação dos documentos utilizados na pesquisa}

\begin{tabular}{|cll|}
\hline Ordem & \multicolumn{1}{c|}{ Descrição do documento } & Ano \\
\hline 1 & Documento institucional - Novos significados e desafios & 2004 \\
2 & Portal institucional da Embrapa/História da Embrapa & 2010 \\
3 & Portal institucional da Embrapa/Embrapa transferência de tecnologia & 2010 \\
4 & Portal institucional da Embrapa/Embrapa Milho e Sorgo & 2010 \\
5 & Política Institucional - Política de negócios tecnológicos & 1998 \\
6 & V Plano Diretor da Embrapa (2008-1 1-23) - Plano institucional Embrapa & 2008 \\
& $\begin{array}{l}\text { Nacional } \\
7\end{array}$ & $\begin{array}{l}\text { Documento institucional - Ciência, tecnologia \& inovação para o setor } \\
\text { agropecuário brasileiro }\end{array}$ \\
\hline
\end{tabular}

Fonte: Elaborado pelos autores.

A utilização combinada de várias fontes de evidências — entrevistas, documentos e observação - possibilitou o cotejo das informações obtidas, conferindo maior rigor aos resultados da pesquisa (Jick, 1979; Eisenhardt, 1989; Yin, 2005), pois o uso de múltiplas fontes de evidências incrementa a validade do constructo, isto é, há uma relação mais consistente entre a teoria e os dados empíricos (Eisenhardt, 1989; Yin, 2005).

No tratamento dos dados, utilizou-se a estratégia de análise de conteúdo qualitativa para organizar, classificar e interpretar os dados coletados. Para a análise dos dados foram estabelecidas categorias com base na literatura (Eisenhardt, 1989). A análise de dados pautou-se, então, no seguinte conjunto de categorias: (i) conexão e integração entre as partes; (ii) capacidade absortiva da receptora; (iii) motivação da receptora para aprender; (iv) domínio de conhecimentos valiosos por parte da fonte; (v) Motivação da fonte para ensinar; e (vi) capacidade da fonte em transferir conhecimentos.

\section{Transferência de conhecimento entre a Embrapa Milho e Sorgo e as empresas licenciadas}

\subsection{Contextualização do caso}

Criada em 1973, e associada ao Ministério da Agricultura, Pecuária e Abastecimento, a Embrapa tem como missão desenvolver atividades de pesquisa, desenvolvimento e inovação a fim de 
incrementar a produtividade e a qualidade de produtos, processos e serviços agropecuários, levando-se em conta as características e peculiaridades de cada região brasileira (Documento 2). É uma empresa pública de direito privado em ciência e tecnologia, com ênfase na geração de tecnologia e inovação (Documentos 5 e 7).

A Embrapa tem vários centros de pesquisa em todo o país. Um deles é o Centro Nacional de Pesquisa de Milho e Sorgo (CNPMS), também conhecido como Embrapa Milho e Sorgo, criado em 1976, e localizado em Sete Lagoas (MG). Seu foco é o desenvolvimento de pesquisa e inovação relacionadas às culturas de milho e sorgo, contando atualmente com uma equipe de cerca de 300 pessoas, entre pesquisadores e pessoal de apoio e administrativo (Documento 4). A estrutura da Embrapa Milho e Sorgo é subdividida em três áreas. Aos núcleos que compõem a área de $\mathrm{P} \& \mathrm{D}$ compete, de modo geral, o processo de melhoramento genético para a geração de novas tecnologias de milho e sorgo. A área de comunicação e negócio, por sua vez, cuida da difusão dos resultados das pesquisas para as empresas licenciadas, da condução dos testes com as sementes geradas pela pesquisa e da avaliação do desempenho dessas tecnologias, além da gestão da comunicação interna, entre outros propósitos. Por fim, a área administrativa assegura o apoio administrativo - recursos humanos, materiais e financeiros - para as outras duas áreas (Documento 4).

Em Sete Lagoas, há ainda outra unidade da Embrapa, o Serviço de Negócio para a Transferência de Tecnologia (SNT) ou a Embrapa Transferência de Tecnologia, cuja função principal é comercializar as sementes geradas pelo CNPMS para as empresas licenciadas que multiplicam e comercializam as sementes de milho e o sorgo. O SNT é, então, o responsável por fazer a intermediação entre a fonte geradora do conhecimento - a pesquisa - e o setor produtivo - receptor desse conhecimento (Documentos 3 e 7). Como a Embrapa não tem uma estrutura para atuar em todas as fases da cadeia produtiva agropecuária, em função de seu escopo, que é essencialmente a pesquisa, o desenvolvimento e a produção de sementes dependem da participação de empresas parceiras que são responsáveis por multiplicar as sementes básicas da instituição em quantidade suficiente para atender ao restante da cadeia (Documentos 2, 3, 4 e 7).

Em função de problemas nos programas de transferência de tecnologia (TT) anteriores (franquia em genética vegetal e oferta pública de cultivares), que vigoraram até 2008, a Embrapa decidiu implementar um novo modelo de transferência de tecnologia. Nesse modelo, que incluiu uma Fundação Triângulo - uma entidade independente, com um histórico de sucesso na associação de empresas produtoras de soja para a transferência de tecnologia a ideia era aproveitar essa experiência com a soja e replicá-la para o caso do milho e sorgo. Assim, em 2008, a parceria entre a Embrapa e esta Fundação foi formalizada mediante um convênio de cooperação técnica que passou a regular as condições da parceria, as obrigações das partes e os projetos a serem elaborados em conjunto (Dressler, 2009).

Nesse sistema, que vigora atualmente, compete ao CNPMS a pesquisa e a geração de novos cultivares. O SNT de Sete Lagoas é responsável pela produção de sementes genéticas para atender à demanda das empresas associadas à Fundação e pelo controle de qualidade desses cultivares. Uma outra unidade do SNT, em Uberlândia, encarrega-se da gestão dos 
contratos de licenciamento firmados com as empresas e, também, das questões comerciais. A Fundação Triângulo, por sua vez, tem, entre outras, as funções de coordenar as empresas associadas, indicar empresas para participarem do licenciamento e participar dos planejamentos conjuntos (Dressler, 2009).

\subsection{Fatores do contexto relacional e transferência de conhecimento}

Em termos de contexto relacional, destaca-se um fator, a conexão e a integração entre as partes, que foi operacionalizado por meio de três atributos, tal como discutido no referencial teórico, a saber: (i) intensidade de vínculos; (ii) confiança; e (iii) proximidade cultural.

Intensidade de vínculos. Partindo do pressuposto de que mudanças no relacionamento entre a Embrapa Milho e Sorgo e as licenciadas poderiam melhorar a conexão entre as duas partes e favorecer o processo de transferência, a partir de 2008, a Embrapa Milho e Sorgo formatou um novo modelo de parceria com as empresas do setor privado responsáveis pela multiplicação das sementes. O objetivo era uma participação mais efetiva destas no desenvolvimento dos cultivares e, assim, eliminar os problemas que geravam uma atmosfera de desconfiança predominante no período das franquias (Entrevistas 1, 4, 6 e 10).

Considerando a necessidade de envolvimento das receptoras nas atividades de P\&D, o CNPMS passou a entregar as sementes para as licenciadas, responsáveis pela condução dos testes em campos próprios, levando-se em conta as condições específicas de solo, clima e de sistema produtivo. Após os testes, cada licenciada poderia escolher as cultivares mais adaptadas e com melhor desempenho para as suas regiões. Em contrapartida, essas empresas passariam a financiar parte das atividades da P\&D, ou seja, os testes de campo (Entrevista 1). Outra expectativa era alcançar um alinhamento entre as tecnologias geradas pela Embrapa e as necessidades das empresas licenciadas e, ao mesmo tempo, reduzir o tempo de disponibilização das sementes para os usuários finais.

No que tange à $\mathrm{P} \& \mathrm{D}$, mesmo havendo previsão contratual de participação das licenciadas na $P \& D$ da instituição, é importante ressaltar que poucas demonstraram interesse na utilização das sementes para testes em campos próprios (Entrevistas 1, 3 e 10). Além do baixo grau de envolvimento na P\&D da Embrapa Milho e Sorgo, poucas licenciadas efetivamente contribuíam com um feedback sobre o desempenho das sementes (Entrevistas 1, 3 e 10). Em muitos casos, essas informações não eram compartilhadas com a Embrapa, pois determinadas licenciadas preferiam mantê-las sob seu domínio, para evitar que outros concorrentes soubessem, por exemplo, quais doenças haviam surgido no momento do plantio ou quais cultivares haviam apresentado bom desempenho (Entrevista 10).

Como as empresas licenciadas não se envolvem com as atividades da fonte, particularmente na P\&D da Embrapa, a lógica do relacionamento entre as partes continua essencialmente a mesma de períodos anteriores, ou seja, a cultivar gerada pela P\&D da Embrapa é idêntica àquela adquirida pelo usuário, havendo pouca contribuiç̧ão das licenciadas para o desenvolvimento da tecnologia (Entrevistas 1, 2, 3, 4 e 10). A eficiência do programa de 
parceria é, assim, comprometida, visto que a Embrapa necessita de informações acerca do desempenho das sementes para realimentar a pesquisa. Em decorrência disso, a instituição somente detecta os problemas com as sementes posteriormente e, muitas vezes, a partir de fontes externas, como a mídia (Entrevista 4). Além do mais, a Embrapa Milho e Sorgo não tem buscado interagir, se comunicar e/ou garantir a efetividade desse feedback por parte das licenciadas (Entrevistas 1 e 4), o que acentua a fraca integração social entre as partes.

Outro aspecto característico dessa relação é a ênfase dada nos aspectos formais do relacionamento entre as partes. O contrato prevê a planificação de algumas atividades conjuntas (Entrevista 3 e 4), mas prioriza muito mais questões formais, tais como o tipo e a quantidade de sementes demandadas pelas licenciadas, o que é insuficiente para estreitar os vínculos e a confiança entre as partes (Entrevista 10). Além disso, os contatos pessoais entre a Embrapa e técnicos das licenciadas são infrequentes, ocorrendo apenas uma ou duas vezes por ano, o que parece ser insuficiente para a troca de experiências e feedback. Some-se a isso a diversidade de interlocutores na Embrapa Milho e Sorgo. Em inúmeras circunstâncias, o licenciado não sabe com quem se comunicar para sanar algum problema ou buscar informações (Entrevista 11).

Confiança. Em razão de um clima de desconfiança e conflito em função do cálculo de royalties em períodos anteriores, a Embrapa modificou a fórmula desse cálculo a fim de minimizar esse problema. O cálculo do valor dos royalties passou a ser feito com base na área (em hectares) efetivamente plantada, evitando-se, assim, possíveis manobras para reduzir o valor a ser pago à instituição (Entrevistas 1, 2 e 3).

A despeito das expectativas de que o novo modelo de licenciamento de tecnologia pudesse resultar em relações mais próximas e de mais confiança entre as partes, as evidências demonstram que isso ainda não aconteceu, sendo o relacionamento caracterizado: (i) por pouca interação e comunicação entre as partes; (ii) pela ênfase da instituição de pesquisa nos aspectos formais de relacionamento; e (iii) pela existência de vários interlocutores na Embrapa Milho e Sorgo, tornando complexo e fragmentado o relacionamento com as licenciadas. Esse relacionamento entre a Embrapa e empresas licenciadas, caracterizado por uma fraca integração social, dificulta a construção de um relacionamento de mais confiança (Entrevistas 1, 3, 4 e 6).

Proximidade Cultural. Se, de um lado, a Embrapa, dada a sua natureza pública, trabalha condicionada por uma série de restrições institucionais, de outro, as licenciadas são privadas, logo suas ações e decisões são mais ágeis e orientadas para o mercado (Entrevistas 1, 2, 4 e 11). Essas diferenças entre os modelos de gestão tendem a gerar dificuldades de entendimento entre as partes, prejudicando o processo de transferência. Por exemplo, os profissionais da Embrapa Milho e Sorgo reconhecem que as exigências impostas pelos órgãos públicos geram enrijecimento e falta de autonomia na atuação da instituição (Entrevistas 2, 4 e 6, documento 6).

Alguns efeitos dessa falta de autonomia são: (i) o relacionamento com as licenciadas é condicionado pela legislação e regulamentações governamentais; (ii) a impossibilidade de se selecionar livremente as empresas, de modo a se excluir aquelas menos capacitadas, pois as empresas são selecionadas mediante edital; (iii) a dificuldade de se ofertar tecnologias exclusivas para atender às demandas de determinadas empresas licenciadas; (iv) a necessidade de 
se atender às diretrizes de pesquisas estabelecidas pelo governo que, em muitos casos, não geram retorno financeiro e/ou são pouco interessantes do ponto de vista da iniciativa privada (Entrevista 1 e 6).

Este último aspecto ilustra a distância e a divergência de valores entre as partes. Para cumprir seu papel social, a Embrapa Milho e Sorgo investe em linhas de pesquisas voltadas para a produção de cultivares para a agricultura familiar e para segmentos que trabalham com tecnologia mais simples e de menor custo (Entrevista 6). As licenciadas tecnológica e comercialmente mais desenvolvidas entendem que isso é um desperdício de recursos e que o desenvolvimento de tecnologias dessa natureza prejudica o desenvolvimento de outras mais sofisticadas (Entrevista 12). Há, assim, uma percepção, por parte dessas licenciadas de que a Embrapa Milho e Sorgo não possui visão mercadológica, pois desenvolve tecnologias que não atendem às necessidades do mercado. Segundo um entrevistado, “(...) empresas novas, com muito menos recursos humanos e genéticos, são capazes de lançar híbridos que atendem mais a esse mercado (...)" (Entrevista 12). O resultado é um descompasso entre a geração de tecnologias pela Embrapa e sua apropriação pelas empresas privadas, pois nem sempre a tecnologia produzida é aquela que interessa ao setor privado.

Em síntese, a baixa intensidade dos vínculos, o baixo nível de confiança e a distância entre as culturas organizacionais da Embrapa e as licenciadas contribuem para uma fraca conexão e integração entre as partes, o que afeta negativamente o processo de transferência de conhecimento. Problemas de confiança, vínculos mais formais e contatos pouco frequentes dificultam o compartilhamento de conhecimento entre a instituição de pesquisa e as empresas licenciadas. A confiança e a intensidade de vínculos são, além disso, afetadas pela distância cultural entre as partes, o que cria dificuldades adicionais para a transferência de conhecimento (quadro 5).

Como descrito anteriormente, na maioria dos casos, a semente entregue pela Embrapa ao licenciado é praticamente a mesma semente comercializada; logo, se pode inferir que é baixo o nível de inovação nos produtos das licenciadas, o que parece ser decorrente de problemas de transferência de conhecimento entre as partes.

\section{Quadro 5}

Síntese das evidências associadas ao contexto relacional

\begin{tabular}{|lll|}
\hline \multicolumn{1}{|c|}{ Categoria } & \multicolumn{1}{c|}{ Atributos } & \multicolumn{1}{c|}{ Evidências } \\
\hline & Intensidade de & - Vínculos sociais reduzidos e interações pouco frequentes e impessoais \\
& vínculos & - Baixo envolvimento na P\&D, feedback reduzido, pouca troca de experiências \\
Conexão e & Confiança & - Sensação reduzida de segurança entre as partes potencializada por laços \\
integração entre & & fracos \\
as partes & Proximidade cultural & - Ausência de significados comuns \\
& & - Sistemas de valores dissonantes entre as partes \\
& & \\
&
\end{tabular}

Fonte: Dados da pesquisa. 


\subsection{Fatores do contexto organizacional e transferência de conhecimento}

Em relação ao contexto organizacional, os fatores mais relevantes para a transferência de conhecimento, do lado da receptora, são: (i) a capacidade absortiva; e (ii) a motivação para aprender. Do lado da fonte, por sua vez, são relevantes: (i) a motivação para ensinar; (ii) a capacidade para transferir conhecimento; e (iii) o domínio de conhecimentos valiosos.

Capacidade absortiva. Em relação à receptora, observou-se que a capacidade absortiva das empresas licenciadas pode variar, especialmente, em função da sua experiência na produção e na comercialização de cultivares de milho, do desenvolvimento interno de P\&D e da presença de pessoal qualificado (Entrevistas 1, 2, 4 e 12). Assim, as licenciadas da Embrapa Milho e Sorgo formam um grupo bastante heterogêneo, variando desde empresas com elevada experiência na produção e comercialização de cultivares até empresas sem experiência (Entrevistas 1, 2, 3 e 11), ou seja, existem empresas com elevada capacidade absortiva e empresas com dificuldades na utilização das tecnologias transferidas pela Embrapa.

Algumas licenciadas têm baixa capacidade absortiva em razão da carência de pessoal qualificado e da ausência de atividades internas de $P \& D$, o que influencia negativamente o processo de transferência de conhecimento entre as partes. Em determinada ocasião, por exemplo, foram ofertadas ao mercado sementes de milho de baixa qualidade, que haviam sido produzidas por determinadas licenciadas, o que, segundo um entrevistado, poderia ser atribuído, entre outras causas, à baixa capacidade absortiva das empresas que as produziram. Por outro lado, existem empresas licenciadas com elevada capacidade absortiva que contribuem para a eficiência do processo de produção das sementes, dada a maior facilidade em assimilar e aplicar a tecnologia e em assegurar a qualidade do produto que será oferecido no mercado.

Os dados evidenciam que há mais proximidade de conhecimento entre a fonte e as receptoras quando estas são empresas de maior porte e desenvolvem P\&D internamente. Quando se trata de empresas menores, elas normalmente não contam com pessoal qualificado, nem como atividades de P\&D internas, o que as distancia em termos de conhecimento da fonte, comprometendo o processo da transferência. Aqui, tem lugar um paradoxo: se, por um lado, as empresas licenciadas de maior porte têm mais proximidade com o domínio tecnológico da fonte, o que potencialmente facilitaria a transferência, por outro, são essas mesmas empresas que, ao menos em tese, teriam menos interesse pelas tecnologias de milho da Embrapa, pois, além de não terem exclusividade na aquisição de cultivares, são capazes de produzir tecnologias no mesmo patamar. Contrariamente, as empresas de menor porte, cujo escopo de conhecimento é mais distante daquele da fonte, seriam, em tese, aquelas com mais interesse nas tecnologias desenvolvidas pela Embrapa.

Domínio de conhecimento valioso. Em relação ao valor do conhecimento e, consequentemente, da atratividade da fonte, ressalte-se que a Embrapa é a mais importante instituição 
de pesquisa agropecuária brasileira, ocupando uma posição de destaque no cenário nacional e internacional em relação à geração de conhecimento. A instituição possui um portfólio de aproximadamente 129 patentes, 168 marcas, 30 softwares e 230 cultivares (Documento 3). Além disso, especificamente, em relação ao CNPMS, a instituição conta com um banco de germoplasma diversificado e tem fácil acesso a outros bancos de material genético de organizações internacionais, podendo, assim, renovar continuamente seu estoque (Documentos 2 e 3). Tudo isso faz da Embrapa uma fonte atrativa de conhecimentos tecnológicos, mas o que se percebe é que, em relação a tecnologias mais novas (por exemplo, sementes transgênicas), ela ainda está em relativo atraso, o que explica, em parte, o paradoxo anteriormente mencionado.

Motivação da receptora. Com relação à motivação da receptora, diversos aspectos parecem influenciar a disposição das licenciadas em adquirir as sementes desenvolvidas pela Embrapa: (i) experiência da instituição na produção de tecnologias agropecuárias; (ii) ampla experiência em projetos de transferência de tecnologia; (iii) oferta de tecnologias de qualidade a um custo razoável; (iv) reconhecimento e reputação nacional da instituição em pesquisa agropecuária; e (v) domínio de um amplo banco de dados de material genético e acesso a outros bancos de dados internacionais.

A despeito dessas motivações, há, por outro lado, alguns fatores que reduzem a atratividade do programa tecnológico da Embrapa Milho e Sorgo e, em consequência, a motivação de uma parcela das licenciadas em adquirir essas tecnologias, como a ausência de exclusividade na aquisição de algumas cultivares.

Embora a Lei de Inovação (Brasil, 2004) preveja em seu art. 6o a possibilidade de a organização pública realizar a transferência de tecnologia por meio de contratação com cláusula de exclusividade ou mediante concessão sem exclusividade, a prática da Embrapa Milho e Sorgo, desde os anos 2000, foi instituir

(...) uma nova sistemática por meio de oferta pública (...) que possibilitava a redução do número de empresas produzindo uma mesma cultivar e atendia de certa forma à demanda das empresas parceiras no sentido de caminhar para uma "exclusividade" ou, ao menos, redução do número de empresas produzindo um mesmo material, com a consequente diferenciação do portfólio entre elas (Entrevista 10).

Tal sistemática ancorava-se na ideia de que a Embrapa Milho e Sorgo tinha “(...) como política a oferta democrática de suas sementes, pelo fato da P\&D ser financiada por recursos públicos. Assim, ela entende que todos os licenciados devem ter acesso aos resultados da pesquisa de forma igualitária, sem contratos de exclusividade com um grupo de clientes" (Entrevista 1).

Como não há exclusividade, isso significa que tanto grandes como pequenas licenciadas adquirem, quase sempre, a mesma semente básica. Assim, como há poucas modificações 
genéticas finais, o que cada licenciada multiplica e comercializa é sempre a mesma semente. Além disso, como a Embrapa não oferece sementes transgênicas, o interesse de parte das licenciadas é ainda menor. A inexistência ou a baixa motivação por parte de algumas licenciadas tem implicações negativas para a transferência do conhecimento, pois, quanto menor a motivação, menor a disposição das receptoras em trabalhar em parceria com a instituição fonte da tecnologia e, portanto, em adquirir essa tecnologia. Assim, as maiores empresas e com mais capacidade absortiva têm menos disposição em aprender e utilizar o conhecimento externo, enquanto as empresas menores e com menos capacidade absortiva têm mais motivação em aprender e participar do processo de transferência.

Motivação da fonte. Quanto à motivação da fonte, parece claro que a Embrapa Milho e Sorgo tem interesse nas atividades de transferência de tecnologia, pois esse é um dos principais processos mediante os quais a instituição cumpre sua missão e reafirma para o governo e para a sociedade a importância de se investir recursos públicos em pesquisa agropecuária (Documentos 1, 2, 4, 5 e 6). Embora haja disposição em participar da transferência, a baixa capacidade absortiva de parte das empresas licenciadas, sobretudo das menores, tende a afetar a disposição da Embrapa em transferir sua tecnologia para essas empresas. Existem ainda outros aspectos que podem concorrer para reduzir essa disposição: o receio de perder o domínio sobre seus conhecimentos em pesquisa agropecuária ou de um uso inadequado da tecnologia pelas licenciadas, como já aconteceu no passado.

Capacidade para transferir conhecimentos. Quanto à capacidade de transferir conhecimentos, ressalte-se a ampla experiência da Embrapa Milho e Sorgo nessa atividade. Além disso, seu capital humano, caracterizado por profissionais de elevada qualificação, com predomínio de mestres e doutores, e de diferentes especialidades (entomologistas, fisiologistas e bioquímicos), combina competências relevantes tanto para a inovação como para a transferência de conhecimento (Documento 7).

Todavia, além desse background, devem-se considerar os mecanismos utilizados para a transferência de conhecimento. Os dados evidenciam que a Embrapa utiliza-se sobremaneira da codificação, visto que a transferência para as empresas licenciadas, em grande parte, é realizada mediante manuais, instruções codificadas e comunicação de caráter impessoal. Ademais, como já descrito, o baixo grau de interação e conexão entre as partes sinaliza um baixo uso de mecanismos mais personalizados de transferência, tais como reuniões, treinamentos e intercâmbio de pessoas. Nesse contexto, é provável que o conhecimento (codificado) transferido não tenha sido suficientemente internalizado e absorvido, o que pode gerar problemas em sua exploração e utilização.

O quadro 6 apresenta uma síntese das evidências relacionadas ao contexto organizacional, tanto da fonte como das receptoras, no processo de transferência do conhecimento. 
Quadro 6

Síntese das evidências associadas ao contexto organizacional da fonte e da receptora

\begin{tabular}{|c|c|c|}
\hline Categoria & Atributos & Evidências Obtidas \\
\hline \multirow{4}{*}{$\begin{array}{l}\text { Capacidade absortiva } \\
\text { da receptora }\end{array}$} & $\begin{array}{l}\text { Nível de qualificação dos } \\
\text { empregados }\end{array}$ & $\begin{array}{l}\text { Heterogeneidade das empresas; carência de pessoal qualificado nas } \\
\text { receptoras de menor porte. }\end{array}$ \\
\hline & $\begin{array}{l}\text { Nível de investimento em } \\
\text { atividades internas de P\&D }\end{array}$ & Atividades de P\&D presentes apenas nas receptoras de maior porte. \\
\hline & $\begin{array}{l}\text { Compatibilidade entre o } \\
\text { conhecimento externo e } \\
\text { o conhecimento prévio da } \\
\text { receptora }\end{array}$ & $\begin{array}{l}\text { Maior compatibilidade nas licenciadas de maior porte que desenvolvem } \\
\text { atividades de P\&D. }\end{array}$ \\
\hline & $\begin{array}{l}\text { Cultura orientada para a } \\
\text { inovação }\end{array}$ & $\begin{array}{l}\text { Elevada capacidade absortiva das receptoras de maior porte com P\&D } \\
\text { interno. }\end{array}$ \\
\hline $\begin{array}{l}\text { Domínio de } \\
\text { conhecimentos } \\
\text { valiosos por parte da } \\
\text { fonte }\end{array}$ & $\begin{array}{l}\text { Reputação na criação } \\
\text { e na transferência de } \\
\text { conhecimentos valiosos }\end{array}$ & $\begin{array}{l}\text { Apesar do excepcional portfólio de geração do conhecimento, há } \\
\text { relatividade na percepção do valor do conhecimento da fonte em função } \\
\text { do atraso em tecnologias mais novas (transgênicos). }\end{array}$ \\
\hline $\begin{array}{l}\text { Motivação da } \\
\text { receptora }\end{array}$ & Interesse em aprender & $\begin{array}{l}\text { - Menor motivação nas licenciadas de maior porte pela falta de } \\
\text { exclusividade e de tecnologias mais avançadas. } \\
\text { - Maior interesse das receptoras de menor porte por dependerem da } \\
\text { tecnologia da fonte para competirem no mercado agropecuário. }\end{array}$ \\
\hline Motivação da fonte & $\begin{array}{l}\text { Interesse em ensinar e } \\
\text { transferir o conhecimento } \\
\text { para outras empresas }\end{array}$ & $\begin{array}{l}\text { - Transferência de tecnologia é parte da missão da Embrapa. } \\
\text { - Há receio de perder conhecimento ou do uso inadequado. } \\
\text { - Motivação pode ser afetada pela baixa capacidade absortiva das } \\
\text { licenciadas. }\end{array}$ \\
\hline $\begin{array}{l}\text { Capacidade } \\
\text { de transferir } \\
\text { conhecimentos }\end{array}$ & $\begin{array}{l}\text { Recursos adequados } \\
\text { para a transferência de } \\
\text { conhecimento }\end{array}$ & $\begin{array}{l}\text { - Elevada qualificação do capital humano da fonte. } \\
\text { - Codificação como mecanismo principal para transferência de } \\
\text { conhecimento. } \\
\text { - Baixo uso de mecanismos personalizados para transferência do } \\
\text { conhecimento. }\end{array}$ \\
\hline
\end{tabular}

Fonte: Dados da pesquisa.

\section{Considerações finais}

O objetivo deste artigo foi compreender e analisar os fatores determinantes no processo de transferência de conhecimento entre uma instituição de pesquisa pública (a Embrapa Milho e Sorgo) e as empresas licenciadas.

Em relação aos diversos fatores que afetam o processo de transferência, foram discutidos, inicialmente, aqueles relacionados ao contexto relacional. No caso analisado, evidenciouse, em primeiro lugar, uma fraca conexão e integração entre as partes resultante de fatores como a baixa intensidade de vínculos e o baixo grau de confiança entre a fonte e receptor, o que dificulta o compartilhamento de conhecimento entre as partes. Entre as razões que podem 
explicar o relacionamento difícil entre as partes, destacam-se a comunicação pouco personalizada e infrequente e, também, a pluralidade de interlocutores. A despeito de haver um setor responsável pela transferência de tecnologia, o relacionamento entre as partes é mediado por vários atores na fonte, tornando o relacionamento entre as partes fragmentado e complexo. Esses resultados são consistentes com a literatura na qual diversos autores argumentam que dificuldades de relacionamento constituem barreiras à efetiva transferência de conhecimento (Szulanski, 1996, 2000; Argote, McEvily e Reagans, 2003; Easterby-Smith, Lyles e Tsang, 2008; Pérez-Nordtvedt et al., 2008). Constatou-se ainda que as diferenças de valores e a ausência de significados comuns entre a Embrapa Milho e Sorgo e as licenciadas representam uma barreira ao fluxo de conhecimento entre as partes.

A relação entre os atributos proximidade cultural, intensidade de vínculos e confiança contribui também para explicar as dificuldades no processo de transferência de conhecimento. Assim, as diferenças entre valores, práticas e objetivos das partes geram conflitos relacionais corroendo ainda mais, como apontado na literatura, a confiança e a intensidade de vínculos entre elas (DeTienne et al., 2004). Ademais, podem dificultar a comunicação entre as partes (Easterby-Smith, Lyles e Tsang, 2008), afetando o processo de transferência de conhecimento (Cummings e Teng, 2003; Van Wijk, Jansen e Lyles, 2008), e até mesmo implicar seu uso inadequado. Ademais, relacionamentos conflituosos afetam, também, a confiança entre as partes. Há, assim, um círculo vicioso que compromete o processo de transferência de conhecimento. Em suma, tais resultados são consistentes com a literatura, segundo a qual relacionamentos difíceis comprometem a eficiência do processo de transferência (Pérez-Nordtvedt et al., 2008).

Com relação aos fatores do contexto organizacional, observou-se que a baixa CA de algumas receptoras influenciou negativamente o processo de transferência de conhecimento entre as empresas. As empresas de menor porte e, em geral, com baixa capacidade absortiva têm mais dificuldades em absorver e utilizar a tecnologia externa. Tais resultados são consistentes com a literatura relativamente ao papel crítico da CA para aquisição, assimilação, transformação e exploração do conhecimento externo (Cohen e Levinthal, 1990; Zahra e George, 2002).

No que concerne à motivação da fonte, para a Embrapa Milho e Sorgo a atividade de transferência de tecnologia é inerente à sua missão. No entanto, em relação à motivação das receptoras, por um lado, a Embrapa é atrativa para as empresas de menor porte, que dependem de suas tecnologias para competirem no mercado agropecuário, mas, por outro, as empresas que têm atividades próprias de P\&D parecem não ver valor nos conhecimentos transferidos pela instituição e, por isso, a motivação dessas empresas tende a ser menor, sobretudo, porque a Embrapa Milho e Sorgo, historicamente, não mantém nenhum contrato de exclusividade de sementes como desejado por algumas licenciadas e, mais recentemente, por não dispor de tecnologias mais avançadas, como cultivares transgênicos de milho. O baixo nível de motivação dessas receptoras em particular tem implicações negativas para a transferência de conhecimento, uma vez que será menor a disposição dessas empresas para trabalhar em parceria com a fonte (Szulanski, 1996, 2000; Love e Roper, 1999; Lin, 2003). 
Da mesma forma que os fatores do contexto relacional estão inter-relacionados, os fatores do contexto organizacional também o são. No caso analisado, a baixa CA das empresas de menor porte tem resultado em certo desinteresse da Embrapa Milho e Sorgo ou, pelo menos, em dificuldades no compartilhamento de seus conhecimentos. Assim, há uma relação entre CA e motivação da fonte para a transferência, como pode ser encontrado na literatura (Szulanski, 2000).

Outro resultado relevante é a relação entre fatores de ambos os contextos, o que é convergente com os estudos de Albino, Garavelli e Schiuma (1999). Por exemplo, a fraca conexão e integração entre as partes afetou sensivelmente a motivação da fonte e da receptora para o compartilhamento de conhecimentos. E, como assinalado na literatura, vínculos mais estreitos e de confiança poderiam minimizar o receio do compartilhamento do conhecimento e aumentar a motivação das partes (Becerra, Lunnan e Huemer, 2008).

A principal contribuição deste artigo para o debate sobre transferência de conhecimento é levar em conta e analisar simultaneamente tanto fatores do contexto relacional quanto do contexto organizacional. Outra contribuição é evidenciar como a inter-relação entre fatores é crítica para se entender o processo de transferência de conhecimento per se, assim como os resultados desse processo.

Do ponto de vista empírico, a análise da dinâmica do processo de transferência e das variáveis que o afetam pode contribuir para que a Embrapa Milho e Sorgo e as licenciadas aperfeiçoem os processos de compartilhamento e de transferência de conhecimento. Em termos de conexão e integração entre as partes, ressalte-se a necessidade de se ampliar a integração entre Embrapa e licenciados, de se institucionalizar uma comunicação mais personalizada e mais frequente com os licenciados e, também, de facilitar o diálogo entre a instituição e os parceiros. No que tange à CA das licenciadas, note-se que os níveis dessa capacidade diferem e, assim, seria prudente acompanhar de maneira mais próxima as empresas com dificuldades para utilizar a tecnologia, permitindo que os técnicos e os profissionais dessas empresas visitem a Embrapa e se capacitem e se envolvam mais diretamente nas atividades de P\&D.

Uma das limitações desta pesquisa é que, a despeito do volume considerável de dados coletados junto à Embrapa Milho e Sorgo, a quantidade de informações obtida junto às empresas receptoras é menor. Mais dados sobre as licenciadas teriam contribuído para compreender melhor as dificuldades e as barreiras para a transferência de conhecimento. Além disso, a abordagem adotada nesta pesquisa, de análise concomitante de vários fatores críticos, pode ter influenciado o nível de profundidade da investigação.

Para finalizar, sugere-se averiguar em termos quantitativos as relações entre fatores de um contexto ou, ainda, os relacionamentos causais entre fatores de contextos diversos. Ademais, novas investigações poderiam analisar também alternativas para a transferência de conhecimento para empresas com baixa capacidade absortiva. 


\section{Referências}

ALBINO, Vito; GARAVELLI, Achille C.; SCHIUMA, Giovanni. Knowledge transfer and inter-firm relationships in industrial districts: the role of the leader firm. Technovation, v. 19, n. 1, p. 53-63, nov. 1999.

ARGOTE, Linda; INGRAM, Paul. Knowledge transfer: a basis for competitive advantage of firms. Organizational Behavior and Human Decision Processes, v. 82, n. 1, p. 150-169, maio 2000.

ARGOTE, Linda; MCEVILY, Bill; REAGANS, Ray. Managing knowledge in organizations: an integrative framework and review of emerging themes. Management Science, v. 49, n. 4, p. 571-582, abr. 2003.

BECERRA, Manuel; LUNNAN, Randi; HUEMER, Lars. Trustworthiness, risk, and the transfer of tacit and explicit knowledge between alliance partners. Journal of Management Studies, v. 45, n. 4, p. 961-713, jun. 2008.

BONOMA, Thomas V. Case research in marketing: opportunities, problems and a process. Journal of Marketing Research, v. 22, n. 2, p. 199-208, maio 1985.

BRASIL. Lei no 10.973, de 2 de dezembro de 2004. Dispõe sobre incentivos à inovação e à pesquisa científica e tecnológica no ambiente produtivo e dá outras providências. Brasília, 2004. Disponível em: <www.planalto.gov.br/ccivil_03/_ato2004-2006/2004/lei/110.973.htm>. Acesso em: 2 jun. 2013.

BRESMAN, Henrik; BIRKINSHAW, Julian; NOBEL, Robert. Knowledge transfer in international acquisitions. Journal of International Business Studies, v. 30, n. 3, p. 439-462, set./dez. 1999.

CHILD, John et al. Access to tacit knowledge by executive retention in cross-border acquisitions. BAR - Brazilian Administration Review, v. 9, n. 3, p. 329-350, jul./set. 2012.

COHEN, Wesley M.; LEVINTHAL, Daniel A. Absorptive capacity: a new perspective on learning and innovation. Administrative Science Quarterly, v. 35, n. 1, p. 128-152, mar. 1990.

CRIBB, André Y.; MAIA, Marcos L. L.; CRIBB, Sandra Lúcia de S. P. Transferência de tecnologia de organizações públicas de pesquisa: uma análise das percepções de empresas agroindustriais no Brasil. In: CONGRESSO DA SOBER “QUESTÕES AGRÁRIAS, EDUCAÇÃO NO CAMPO E DESENVOLVIMENTO, 44, 2006, Fortaleza. Anais... Fortaleza: Sociedade Brasileira de Economia e Sociologia Rural, 2006. p. 395.

CUMMINGS, Jeffrey L.; TENG, Bing-Sheng. Transferring R\&D knowledge: the key factors affecting knowledge transfer success. Journal of Engineering and Technology Management, v. 20, n. 1-2, p. 39-68, jun. 2003.

DETIENNE, Kristen B. et al. Toward a model of effective knowledge management and directions for future research: culture, leadership, and CKOs. Journal of Leadership and Organizational Studies, v. 10, n. 4, p. 24-43, jan. 2004. 
DRESSLER, Marcelo. Gestão dos relacionamentos numa rede interorganizacional: o caso do segmento milho da Embrapa e seus licenciados. Dissertação (mestrado) - Programa de Pós-Graduação em Administração, Pontifícia Universidade Católica de Minas Gerais, Belo Horizonte, 2009.

EASTERBY-SMITH, Mark; LYLES, Marjorie A.; TSANG, Eric W. K. Inter-organizational knowledge transfer: current themes and future prospects. Journal of Management Studies, v. 45, n. 4, p. 677690, jun. 2008.

EISENHARDT, Kathleen M. Building theories from case study research. Academy of Management Review, Standford, v. 14, n. 4, p. 532-550, out. 1989.

EMBRAPA TRANSFERÊNCIA DE TECNOLOGIA. Histórico da Embrapa Transferência de Tecnologia. Disponível em: <http://snt.sede.embrapa.br/historico/>. Acesso em: 1o set. 2010.

EMPRESA BRASILEIRA DE PESQUISA AGROPECUÁRIA. Ciência, tecnologia e inovação para o setor agropecuário brasileiro: contribuições e visão do futuro da Empresa Brasileira de Pesquisa Agropecuária. Brasília, 2002. Disponível em:<www22.sede.embrapa.br/unidades/uc/sge/ciencia_tecnologia_inovacao_setoragbrasileiro.pdf $>$. Acesso em: 10 set. 2010.

EMPRESA BRASILEIRA DE PESQUISA AGROPECUÁRIA. Embrapa Milho e Sorgo. Disponível em: $<$ www.embrapa.br/a_embrapa/unidades-de-pesquisa-e-de-servicos/unidades-de-pesquisa-de-produtos/cnpms/>. Acesso em: 1ํo set. 2010.

EMPRESA BRASILEIRA DE PESQUISA AGROPECUÁRIA. Novos significados e desafios. Brasília: Embrapa Informação Tecnológica, 2004. Disponível em: <www.embrapa.br/publicacoes/institucionais/ relatorios-de-atividades/Embrapa >. Acesso em: 3 ago. 2011.

EMPRESA BRASILEIRA DE PESQUISA AGROPECUÁRIA. V Plano Diretor da Embrapa 2008-20112023. Brasília: Secretaria de Gestão e Estratégia, 2008. Disponível em: <www.embrapa.br/publicacoes/institucionais/V-PDE.pdf/view>. Acesso em: 3 ago. 2010.

EMPRESA BRASILEIRA DE PESQUISA AGROPECUÁRIA. Política de negócios tecnológicos. Brasília: 1998. Disponível em: <http://hotsites.sct.embrapa.br/proeta/informacoes/politica-de-negociostecnologicos-embrapa/Poliitica\%20de\%20Negocios\%20Tec.\%20Embrapa.pdf/view>. Acesso em: 10 set. 2010.

EMPRESA BRASILEIRA DE PESQUISA AGROPECUÁRIA. Portal institucional. Disponível em: < http:// hotsites.sct.embrapa.br/pme>. Acesso em: 10 maio 2010.

GREENWOOD, Ernest. Metodología de la investigación social. Buenos Aires: Paidós, 1973.

GUPTA, Anil K.; GOVINDARAJAN, Vijay. Knowledge flows within multinational corporations. Strategic Management Journal, v. 21, n. 4, p. 473-496, abr. 2000.

HANSEN, Morten T.; NOHRIA, Nitin; TIERNEY, Thomas. What's your strategy for managing knowledge? Harvard Business Review, v. 77, n. 2, p. 106-116, 1999.

JICK, Todd D. Mixing qualitative and quantitative methods: triangulation in action. Administrative Science Quarterly, v. 24, n. 4, p. 602-611, dez. 1979. 
LIN, Bou-Wen. Technology transfer as technological learning: a source of competitive advantage for firms with limited R\&D resources. R\&D Management, v. 33, n. 3, p. 327-341, jun. 2003.

LOVE, James H.; ROPER, Stephen. The determinants of innovation: R\&D, technology transfer and networking effects. Review of Industrial Organization, v. 15, n. 1, p. 43-64, aug. 1999.

MALIK, Khaleel. Aiding the technology manager: a conceptual model for intra-firm technology transfer. Technovation, v. 22, n. 7, p. 427-436, jul. 2002.

PÉREZ-NORDTVEDT, Liliana et al. Effectiveness and efficiency of cross-border knowledge transfer: an empirical examination. Journal of Management Studies, v. 45, n. 4, p. 714-744, jun. 2008.

SIMONIN, Bernard L. Transfer of marketing know-how in international strategic alliances: an empirical investigation of the role and antecedents of knowledge ambiguity. Journal of International Business Studies, v. 30, n. 3, p. 463-490, set./dez. 1999.

SMILOR, Raymond W.; GIBSON, David V. Technology transfer in multi-organizational environments: the case of R\&D consortia. IEEE Transactions on Engineering Management, v. 38, n. 1, p. 3-13, fev. 1991.

SUN, Peter Y.; SCOTT, John L. An investigation of barriers to knowledge transfer. Journal of Knowledge Management, v. 9, n. 2, p. 75-90, 2005.

SZULANSKI, Gabriel. Exploring internal stickiness: impediments to the transfer of best practice within the firm. Strategic Management Journal, v. 17, n. Special Issue, p. 27-43, Winter 1996.

SZULANSKI, Gabriel. The process of knowledge transfer: a diachronic analysis of stickiness. Organizational Behavior and Human Decision Processes, v. 82, n. 1, p. 9-27, maio 2000.

VAN WIJK, Raymond; JANSEN, Justin J. P.; LYLES, Marjorie A. Inter and intra-Organizational knowledge transfer: a meta-analytic review and assessment of its antecedents and consequences. Journal of Management Studies, v. 45, n. 4, p. 830-853, jun. 2008.

VINDING, Anker L. Interaction between firms and knowledge institutions. Product innovation, interactive learning and economic performance. Research on Technological Innovation and Management Policy, v. 8, p. 257-283, 2004.

YIN, Robert K. Estudo de caso: planejamento e métodos. 3. ed. Porto Alegre: Bookman, 2005.

YIN, Robert K. The case study crisis: some answers. Administrative Science Quarterly, Cornell University, v. 26, n. 1, p. 58-65, mar. 1981.

ZAHRA, Shaker A.; GEORGE, Gerard. Absorptive capacity: a review, reconceptualization and extension. Academy of Management Review, v. 27, n. 2, p. 185-203, abr. 2002.

José Márcio de Castro é doutor em administração e professor adjunto no Programa de Pós-graduação em Administração da Pontifícia Universidade Católica de Minas Gerais (PUC-MG). E-mail: josemarcio@ pucminas.br. 
Daniela Martins Diniz é mestre em administração e pesquisadora da Fundação Dom Cabral (FDC) e funcionária da Pontifícia Universidade Católica de Minas Gerais (PUC-MG). E-mail: dani@pucminas.br.

Roberto Gonzalez Duarte é doutor em administração e professor adjunto na Faculdade de Ciências Econômicas e Administrativas da Universidade Federal de Minas Gerais (Face/UFMG). E-mail: rgonzalezduarte@gmail.com.

Marcelo Dressler é mestre em administração e analista A da Embrapa Produtos e Mercado — Escritório de Sete Lagoas (MG). E-mail: Marcelo.dressler@embrapa.br.

Rodrigo Baroni de Carvalho é doutor em ciência da informação e professor adjunto no Programa de Pósgraduação em Administração da Pontifícia Universidade Católica de Minas Gerais (PUC-MG). E-mail: baroni@pucminas.br. 